\title{
Parental Emotional Attachment and Birth Order as Correlates of Undergraduates Sexual Orientation in Selected Universities in Osun State
}

\author{
Oluwatosin S.A, Ogunnoiki A.O. \\ Department of Educational Foundations and Counselling Obafemi Awolowo University, Ile- ife. \\ *Corresponding Author: Oluwatosin S.A, Department of Educational Foundations and Counselling \\ Obafemi Awolowo University, Ile- ife, Nigeria
}

\begin{abstract}
The study investigated parental emotional attachment, birth order and sexual orientation. These were with a view to providing informationon factors that could contribute to sexual orientation among undergraduates in selected universities in Osun State. The study adopted survey research design. The sample size was 900 undergraduates who were selected using multi-stage sampling procedure. Three universities were selected using purposive sampling technique; using ownership as basis for selection (one Federal, one State and one Private). Thirteen faculties were selected across three selected universities by proportionate stratified sampling technique (seven faculties from federal, four from state and two from private universities). Three hundred students were selected from each of the universities using convenience sampling technique. An instrument titled Correlates of Sexual Orientation Questionnaire (CSOQ) was used to collect data from the respondents. Pearson Product Moment Correlation Coefficient and Chi square were employed to analyse the data. It was revealed that there was a positive significant relationship between parental emotional attachment $(r=0.085, p<0.05)$ and sexual orientation; it was also revealed that there was a positive significant relationship between birth order $\left(\chi^{2}=12.11, p<0.05\right)$; and sexual orientation.
\end{abstract}

Keywords: Sexual Orientation, Parental Emotional Attachment, Birth Order, Undergraduates, University

\section{INTRODUCTION}

In all societies around the world, there are various recognized patterns of sexual attraction and sexual relationship among mature individuals depending on their varied sexual preferences. Such relationship could be homosexual, heterosexual or bisexual. Heterosexuality seems to be widely regarded as the naturally acceptable sexual orientation while homosexuality and bisexuality are often generally considered to be aberrant, unnatural and immoral especially in most part of the world. Meanwhile, the three broad sexual orientations are believed to be equally old. That, the homosexual and bisexual practices are not recently invented sexual practices: they have been in existence even in ancient civilizations and among the elites of the societies (Zive, n.d.). However, such practices did not gain public acceptance as they were "not something to be proud of".

Sexual orientation refers to a person's emotional and sexual attraction to a particular sex (male or female). Sexual orientation is perceived to be typically divided into three categories: heterosexuality, (the attraction to individuals of the opposite sex); homosexuality, (the attraction to individuals of one's own sex); and bisexuality (the attraction to individuals of either sex) Heterosexuals and homosexuals may also be referred to informally as 'straight' and 'gay' respectively.

Africa which is perceived as being a relatively more conservative society and Nigeria being a hetero normative society, it supports heterosexuality as the norm such that sexual orientation different from heterosexuality are not only seen as an ordinary deviance but are often treated as an abomination and a curse. There seems to be a loud opposition against homosexuality and bisexuality. While this does not imply that a typical sexual orientations are new phenomena in the continent, the pressure to provide legal protection for homosexuals and bisexuals is commonly viewed as a form of Western cultural imperialism and neocolonialism. Laws criminalizing same-sex relationship, according to 
Baudh (2008) are differently worded as gross indecency, debauchery, buggery, and carnal intercourse against the order of nature.

In modern Nigeria, same-sex relationship has over time continued to generate serious debates in Nigeria. Although the furor relating to this sexual relationship has been tentatively laid to rest with the passage of the anti-homosexual bill into law by the Nigerian National Assembly, the controversy it has thrown-up is far from over. On September 28th, 2011, a bill prohibiting same-sex marriage in Nigeria, saying the practice cannot be allowed on moral and religious grounds. Thereafter, the bill was unanimously endorsed by the legislators; subsequently, a fourteen year prison sentence was stipulated as the punishment for anyone who violates the law (Atoi, 2013). Homosexuality is described as "an offence against the order of nature" and is liable to punishment with a jail term. It goes further to talk about "unlawful carnal knowledge" of a man (anal sex) and is also punishable by law (Atsenuwa, 2003).

However, while some group of people view this law as a gross violation of their fundamental human rights, others consider the practice of same-sex relationships as an aberration and a blatant violation of the hallowed African traditional cultural values and the fundamental tenets of their religious beliefs. Consequently, in spite of the anti-gay law, it is suspected that homosexuality, lesbianism and bisexuality are practiced and condoned in different settings in Nigeria, specifically among undergraduates going by sex tape of students that usually go viral on internets in this regard. Meanwhile, Nigeria is a signatory to many United Nations documents on Human Rights, population and development, there is no form of commitment towards the implementation of the agreements. The International Conference on Population and Development (ICPD) (Presser, 2000.) program of action clearly outlines the sexual and reproductive rights of all humans. It emphasizes equity and respect for the rights of individuals.

Beyond the legal perspective, as children grow up in Nigeria society, they are introduced to a wide range of knowledge about sexual behaviour by their parents, siblings, society and peers. Part of their education addresses the ideas of sexual orientation and/or preference. The inherent messages in this education are that a person is heterosexual (sexually attracted to members of opposite sex), homosexual (sexually attracted to members of the same sex) or bisexual (sexually attracted to members of both sexes). Sexual orientation has been said to refer to a person's erotic and emotional orientation toward members of his or her own sex or member of the other sex (Herek, 1994). It is thought to be an expression of physical sexual attraction or identity. Sexual orientation falls along a continuum (Sholeye, 2013).

Most children begin experiencing sexual attraction sometimes during late childhood or early adolescence. The object of their attraction is usually a member of the opposite sex, but it seems some youngsters are attracted to people of the same sex. Children with gender identity disorder (in which a person is dissatisfied and uncomfortable with his or her biological sex) dress and behave in ways that are more typical of the opposite sex. Children like this may develop a homosexual orientation, this is one of the speculations of this study. Homosexuality, according to Parasar (2007), is a sexual orientation characterized by sexual attraction or romantic love exclusively for people who are identified as being of the same-sex. People who are homosexual, particularly males, are known as 'gay', while females are known as 'lesbian'. This practice has been widely viewed by different societies as abnormal, deviant and/or an abomination; thus, the development of a healthy homosexual identity may be challenged because of the existing social attitudes towards it.

Sexual orientation plays an important role in the development of human behaviour and human personality. A person's sexual orientation is a fundamental aspect of the person's sexuality and identity. Many people identify themselves as having a certain sexual orientation based on who they are attracted to or fall in love with. One may be inquisitive to know the reason why some undergraduates are bisexual or homosexual in Nigeria instead of being heterosexual as the culture and society demands of them. This is the issue of concern in this study. Could it be that some psychosocial factors like parental emotional attachment and birth order have been responsible for its practices (homosexuality and bisexuality)?. It is not very certain how these variables have explained or influence the development of sexual orientation of the undergraduates. The probable identified factors are hereby explained as follows: 
Parental emotional attachment can be said to be a feeling of affection of the care giver or parents to a child. This affection is said to be determined by the love, care and attitude shown to a child by the carer or parents. According to attachment theory, a child forms a strong emotional bond with caregivers during childhood with lifelong consequences (Bretherton, 1992). Parent-child relationships are embedded in a broader social system, such as the extended family, school and neighborhood. This broad social system affects parenting styles and patterns of parent-child interactions. Due to the fact that all societies expect certain characteristics and behaviors from people in order to function adequately as members of their society, functional parenting, apart from universal biological practices such as caring for and protecting children, often includes specific practices related to the values and standards prevailing in the society (Camras\& Chen, 2008). Given that cultures differ with respect to ideas about parenting, it is reasonable to assume that cultural differences can be found also with respect to attachment styles. Some evidences indeed were found that individuals from diverse cultures may endorse different romantic attachment styles (Schmitt et al., 2004).

Birth order is another variable that is being considered in this study. Birth order refers to the position in which a child occupies in the family. It is the unique relationship that exist amongst siblings which brings about the development of a romantic relationship. Studies have shown that there is a unique relationship between elder brothers or elder sisters and homosexuality in males and females (gay and lesbian). Homosexual females tend to have significant majority of older sisters and homosexual males tend to have significant majority of older brothers. In a study conducted by (Bogaert , 2006), it indicated that homosexual men have significantly more older male siblings than the homosexual women, who, in turn, have significantly more siblings than heterosexual men. It will be interesting to know if the number of girls in a family would determine the number of lesbians and if the number of boys in a family would determine the number of gays.

University environment allows some degree of freedom from parental control and also encouraged peer influence. It is an environment where people from various sexual background blend, it provides opportunity of meeting with people who might have mixed with western culture. These undergraduates may get involved in various sexual prefixes. However, it is believed that the extent to which these factors determine sexual orientation varies. Civil society groups, non-governmental organizations, educators and health workers have partnered with governments at various levels, to produce training materials on comprehensive sexuality education for secondary school students and out of school youths. Some programmes discuss sexual orientation, while others completely ignore it. In any case, undergraduates in Nigerian universities have limited sexuality education and this might influence the extent to which parental emotional attachment and birth order relate to their sexual orientation.

Living in a heterosexist society inevitablyposes challenges to people with non- heterosexualorientations. Many lesbian, gay, and bisexual people facesocial stigma, heterosexism, violence, and discrimination (Herek, 2009; Mays \& Cochran, 2001; Meyer, 2003). These challenges may precipitate a significant degree of stress for lesbian, gay, and bisexual people. Many of whom may be tolerated only when they keep to themselves (Diplacido, 1998). This attraction varies among the present day youths especially undergraduates who engage in various kinds of sexual activities. Apart from heterosexual orientation, other sexual orientations are considered to be abnormal especially in Nigeria. It is assumed that undergraduates engage in different kinds of sexual orientation but it has not been established whether they equally engage in same sex relationship such as homosexuality. If they are, what are those factors associated with the development of these sexual orientations. In recent past during the agitation for the passage of bill to legalize same sex marriage, it was observed by this researcher that some people agitating for the passage of bill to legalize same sex marriage were passionately and emotionally defending the status that it was their natural make up. Thus, suggesting that there might be some factors in their developmental process that are associated with this; this also need to be investigated. However, it is perceived that undergraduates with sexual orientation aside from heterosexuality will continue to suffer stigmatization amongst their colleagues and lecturers which might lead to their absence from classes and which might affect their performance in their studies and perhaps they may also develop psychological problem if their situation is not objectively addressed .This can therefore be a source of concern to people in this category if they associate their sexual orientation to their physiological and psychological make-up, suggesting that association of 
factors in their developmental process such as parental emotional attachment and birth order maybe associated with sexual orientation but this has not been empirically established, hence this study.

\section{Purpose OF The STUdy}

The specific objectives of the study are to:

a. Investigate the relationship between parental emotional attachment and sexual orientation

b. investigate the relationship between birth order and sexual orientation

\section{RESEARCH HYPOTHESES}

1. There is no significant relationship between parental emotional attachment and sexual orientation

2. There is no significant relationship between birth order and sexual orientation

\section{Method}

\subsection{Research Design}

The study adopted descriptive research design.Based on the fact that all undergraduates cannot be possibly reached.

\subsection{Sample}

A sample size of 900 undergraduate students was selected for the study using multi-stage sampling technique. Three universities were selected for the study using ownership as the basis for selection. This culminated in the selection of one federal, one state, and one private universities. Furthermore, the private university selected was done using non-faith based as the selection criterion based on the tendency of the faith-based ones to over-protect their school image by their refusal on accessibility on the students on information relating to sexual matters. Thirteen faculties were selected from the universities selected by proportionate sampling technique (seven faculties from federal, four faculties from state and two faculties from private). Three hundred students were selected from the faculties in each of the universities using convenience sampling technique.

\subsection{Research Instrument}

An instrument tagged "Correlates of Sexual Orientation Questionnaire" (CSOQ) was used to collect data for the study. The validity of the instrument was ascertained by tests expert.The questionnaire was made of three sections. Section A contains items on demographic variables such as: age, sex, position in the family, religion, number of children in the family. Section B contained 46 items on parental emotional attachment. The items in the instrument was structured along "Strongly Agree (SA), Agree (A), Disagree (D) to Strongly Disagree (SD)" response pattern.

\subsection{Data Collection}

The questionnaires were administered on undergraduates in Osun State by the researchers, with the help of research assistants and representative of each of the faculties visited. In order to facilitate the success of the questionnaire administration, the researchers ensuredthe cooperation of some class representatives who also assisted in the administration of the questionnaires. Copies of the questionnaire were distributed to the respondents. A total of 900 copies of questionnaire were originally designed for the administration (i.e. 300 copies questionnaires for each universities). However, the researchers were able to retrieve 851 copies. The others were either not well completed or could not be retrieved. However, the questionnaire administration exercise was a success because the study recorded about $94 \%$ return rate. The data collection lasted for two weeks.

The data that were generated from the respondents were analyzed using descriptive and inferential statistics to test the hypotheses. Specifically hypotheses 1 and 2 were tested using Pearson Product Correlation and Chi square. The hypotheses were tested at the level of 0.05 level of significance.

\section{RESULTS}

Hypothesis 1: There is no significant relationship between parental emotional attachment and sexual orientation 
Parental Emotional Attachment and Birth Order as Correlates of Undergraduates Sexual Orientation in Selected Universities in Osun State

To test this hypothesis, participants' responses to Section B of CSOQ which measure students' parental emotional attachment were scored. On this scale the minimum and maximum score obtained were respectively 46 and 203 with mean and standard deviation $(\bar{X}=115.45, \mathrm{SD}=22.57)$. The total score obtained on parental emotional attachment and sexual orientations scale were correlated using Pearson correlation coefficient. The results were as presented in Table1.

Table1: Relationship between Students' Parental Emotional Attachment and Sexual Orientation

\begin{tabular}{|c|c|c|c|c|c|}
\hline Variables & $\mathrm{N}$ & Mean & Std. Deviation & $\mathrm{R}$ & $\mathrm{P}$ \\
\hline Sexual Orientation & 851 & 15.0764 & 3.81854 & \multirow[t]{2}{*}{0.085} & \multirow[b]{2}{*}{$<0.05$} \\
\hline $\begin{array}{l}\text { Parental Emotional } \\
\text { Attachment }\end{array}$ & 851 & 115.4491 & 22.57248 & & \\
\hline
\end{tabular}

Results as presented in Table 4 showed a significant relationship between scores obtained on parental emotional attachment and sexual orientation scales with Pearson correlation coefficient $(r=0.085)$. Attempt was further made to determine the dependency of students' sexual orientation on parental emotional attachment level. Parental attachment levels were determined with reference to the obtained descriptive statistics.

On the parental emotional attachment scale, scores that ranged between the minimum and the mean minus one standard deviation (46-93) is regarded as low emotional attachment while scores that are greater than the mean minus one standard deviation but lesser than the mean plus one standard deviation (94-137) were regarded as moderate emotional attachment and scores that ranged between the mean plus one standard deviation and maximum score was regarded as high parental emotional attachment (138-20)

Table2: Parental Emotional Attachment Level

\begin{tabular}{|l|l|l|l|}
\hline $\begin{array}{l}\text { Parental Emotional Attachment } \\
\text { Level }\end{array}$ & Frequency & Valid Percent & Cumulative Percent \\
\hline Low & 131 & 15.5 & 15.5 \\
\hline Moderate & 595 & 70.5 & 86.0 \\
\hline High & 118 & 14.0 & 100.0 \\
\hline Total & 844 & 100.0 & \\
\hline
\end{tabular}

The relationship between levels of parental emotional attachment and sexual orientation was determined using chi-square. The results were as presented in Table3.

Table3: Relationship between parental emotional attachment levels and students' sexual orientation types

\begin{tabular}{|l|l|l|l|l|l|l|}
\hline \multirow{2}{*}{$\begin{array}{l}\text { Parental Emotional } \\
\text { Attachment Level }\end{array}$} & \multicolumn{3}{|c|}{ Students' Sexual Orientation } & $\boldsymbol{\chi}^{2}$ & $\mathrm{df}$ & $\mathrm{p}$ \\
\cline { 2 - 5 } & Heterosexual & Homosexual & Bisexual & & & \\
\hline Low & $75(57.3 \%)$ & $12(9.2 \%)$ & $46(35.1 \%)$ & & & \\
\hline Moderate & $470(79.0 \%)$ & $16(2.7 \%)$ & $109(18.3 \%)$ & 41.29 & 4 & $<0.05$ \\
\hline High & $86(72.9 \%)$ & $5(4.2 \%)$ & $25(21.2 \%)$ & & & \\
\hline
\end{tabular}

The result as presented in Table 7 showed that with the obtained chi-square value $\left(\chi^{2}=41.29, p<.05\right)$, the relationship between students' parental emotional attachment and students' sexual orientation is significant. That is students' sexual orientation significantly depends on parental emotional attachment level.

Hypothesis 2: There is no significant relationship between birth order and sexual orientation.

To test this hypothesis, students' birth order were grouped into three categories that includes "First Born", "Last Born" and those that were neither first or last born and they were in this study categorized as "Middle Born". The dependency of sexual orientation on birth order was then determined with the use of Chi-square statistic. The results were as presented in Table.

Table4: Relationship between birth order and sexual orientation

\begin{tabular}{|l|l|l|l|l|l|l|}
\hline \multirow{2}{*}{$\begin{array}{l}\text { Students' Birth } \\
\text { Order }\end{array}$} & \multicolumn{3}{|c|}{ Students Sexual Orientation } & \multirow{2}{*}{ 点 } & Df & P \\
\cline { 2 - 4 } & Heterosexual & Homosexual & Bisexual & & & \\
\hline First & $186(74.1 \%)$ & $12(4.8 \%)$ & $53(21.1 \%)$ & \multirow{2}{*}{12.11} & 4 & $<0.05$ \\
\hline Second & $392(77.9 \%)$ & $15(3.0 \%)$ & $96(19.1 \%)$ & & & \\
\hline Last & $60(61.9 \%)$ & $6(6.2 \%)$ & $31(32.0 \%)$ & & & \\
\hline
\end{tabular}


The result as presented in Table 11 showed that with the obtained chi-square value $\left(\chi^{2}=12.11, p\right.$ $<.05$ ), the relationship between students' birth order and students' sexual orientation is significant. That is students' sexual orientation is statistically significantly depends on birth order.

\section{DISCUSSION}

The findings from the first hypothesis indicated that parental emotional attachment is positively correlated with sexual orientation. The findings is in concordance with the studies by Shu and Lung (2007) which concluded that "paternal protection and maternal care were determined to be the main vulnerability factors in the development of homosexual males." Key factors in the development of homosexuals were "paternal attachment, introversion, and neurotic characteristics". Ridge (1998) also reported that homosexual males reported more positive early relationships with mothers than did homosexual females. Rahman et al. (2008) found increased in the state of being fertile among maternal aunts of gay men only among white participants, with non-white heterosexual individuals displaying increased fecundity among most other kin types. The present finding is in agreement with (Zietsch et al., 2008) that found out that genes predispose some individuals towards homosexuality, they compensate for the associated decrement in reproduction by increasing the reproductive success of heterosexual individuals in which the same genes reside. As postulated by Sims (2009) that children who experience carers who are consistently rejecting, threatening and unresponsive to the baby's needs are at risk of developing a disorganized attachment style.This simply implies that children with a disorganized attachment styles may not have a consistent way of expressing their needs and feelings to carers or parents. Harrison (2003) also postulated that when carersare able to understand a child's cues and respond to the child's physical and social needs in a caring and consistent way this establishes a styles of attachment that is called secure attachment. This can be said to mean that a child with a secure attachment style would have an organized attachment styles which simply means that the child would have a positive sexual orientation while a child with a disorganized attachment styles might have a negative sexual orientation.

The findings from the second hypothesis indicated that there is a significant relationship between birth order and sexual orientation. The present findings is in line with the studies of Bogaert (2005), Blanchard; Put; Jordan (2006), Pillard et al (1981), Benishay (1993), Bailey and Bell (1993), Bailey et al. (1999) Blanchard, 2008; Bogaert \& Skorska, 2011), which indicated that homosexual men have significantly more older male siblings than the homosexual women, who, in turn, have significantly more siblings than heterosexual men. They also found out that found that both lesbians and gay men were more likely than heterosexual men and women to have gay siblings, with monozygotic twins yielding the highest concordance rates in orientation, as would be expected assuming a genetic predisposition to the trait and that the number of a man's (but not a woman's) older brothers increases his likelihood of being gay, each older brother increasing the odds by approximately $33 \%$ above the base rate of $2-3 \%$.

\section{CONCLUSION}

This study indicated that parental emotional attachment and birth order are capable factors in influencing undergraduates choice of sexual orientation.

\section{RECOMMENDATION}

In other to reduce the rate at which students fail and probably drop out of school as a result of their choice of sexual orientation,counselors and counseling centers in higher institutions should be resourced to be able to handle the issues of student sexuality including homosexuality and bisexuality.Training workshops on sexual orientation should be intensified for teachers as well as school administrators for them to be well informed with current trends such as homosexuality and bisexuality in schools. Teachers and parents should act as guidance to students through proper monitoring and care with listening ears. Student accessibility to appropriate and accurate information regarding students' sexuality should be increased at early stages through library and Internet resources as well as workshops and forums.Parents should try as much as possible to know the types of friends their children associate with in order to check mate them in most of their attitude.Parents should also check the behaviors of their children as they grow up. Parents should Endeavour to know the sex of the persons their children are easily attracted to. Parents and care givers are admonished to exhibit 
love, care and affection towards their children as this will help them to have a positive sexual orientation .Government should also establish effective rehabilitation centers for homosexuals and bisexuals in order to assist them recover from their deviant behavior.

\section{REFERENCES}

[1] Atoi, E. N., \& Ojedokun, U. A. (2013). Same-Sex Relationship Among Tertiary Institution Students in Ibadan. Journal of Pan African Studies, 5(10), 63-80.

[2] Atsenuwa, V. A. (2003). Sexuality And The Law. Paper presented at action groups on Adolescent Health's Public Lecture. Lagos University Teaching Hospital, Idi Araba, Lagos, May 30 2003.unpublished documents.

[3] Baudh, S. (2008).,,Human rights and the criminalization of consensual same sex sexual acts in the commonwealth. South and Southeast Asia" Working paper (May 2008).

[4] Bogaert, A. F. (2006). Biological versus non biological older brothers and men's sexual orientation. Proceedings of the National Academy of Sciences, 103, 10771-10774.

[5] Bretherton, I. (1992). Attachment and bonding. In Handbook of social development (pp. 133-155).Springer US.

[6] Camras, L., Kolmodin, K., \& Chen, Y. (2008). Mothers' self-reported emotional expression in Mainland Chinese, Chinese American and European American families. International Journal of Behavioral Development, 32(5), 459-463.

[7] DiPlacido, J. (1998). Minority stress among lesbians, gay men, and bisexuals: A consequence of heterosexism, homophobia, and stigmatization. Sage Publications, Inc.

[8] Mays, V. M., \& Cochran, S. D. (2001). Mental health correlates of perceived discrimination among lesbian, gay, and bisexual adults in the United States. American Journal of Public Health, 91(11), 18691876.

[9] Parasar, A. (2007). Homosexuality In India-The Invisible Conflict.

[10] Presser, H., \&Sen, G. (2000).Women's empowerment and demographic processes: Moving beyond Cairo. Oxford University Press.

[11] Herek, S. J (1994). Sexual orientation. Understanding Human Sexuality.5th Edition New York.McGrawHill Inc.

[12] Herek, G. M. (2009). Hate crimes and stigma-related experiences among sexual minority adults in the United States: Prevalence estimates from a national probability sample. Journal ofInterpersonal Violence, 24, 54-74. doi:10.1177/0886260508316477.

[13] Schmitt, D. P., Alcalay, L., Allensworth, M., Allik, J., Ault, L., Austers, I., \&Braeckman, J. (2004). Patterns and universals of adult romantic attachment across 62 cultural regions: Are models of self and of other panculturalconstructs?.Journal of Cross-Cultural Psychology, 35(4), 367-402.

[14] Sholeye, O., \&Kuponiyi, O. T. (2013).Sexual orientation and the Nigerian society.Scientific Research and Essays, 8(5), 202-204.

\section{AUTHOR's BIOGRAPHY:}

S.A. Oluwatosin is a researcher in the department of Educational Foundations and Counselling, Obafemi Awolowo University, Ile Ife. Nigeria.

A.O. Ogunnoiki is a researcher in the department of Educational Foundations and Counselling, Obafemi Awolowo University, Ile Ife. Nigeria.

Citation: Oluwatosin S.A, Ogunnoiki A.O. " Parental Emotional Attachment and Birth Order as Correlates of Undergraduates Sexual Orientation in Selected Universities in Osun State" International Journal of Humanities Social Sciences and Education (IJHSSE), vol 5, no. 1, 2018, pp. 33-39. doi: http://dx.doi.org/10.20431/2349-0381.0501006.

Copyright: () 2018 Authors. This is an open-access article distributed under the terms of the Creative Commons Attribution License, which permits unrestricted use, distribution, and reproduction in any medium, provided the original author and source are credited. 